\title{
Sensorless vector control of a permanent magnet synchronous motor
}

\author{
Ruslan Zhiligotov ${ }^{1}$, Vyacheslav Shestakov ${ }^{1}$, Vladymyr Sosnin ${ }^{1}$, and Evgeniy Popkov ${ }^{1}$ \\ ${ }^{1}$ Peter the Great St.Petersburg Polytechnic University, Polytechnicheskaya, 29, St. Petersburg, \\ 195251, Russia
}

\begin{abstract}
The most common control system for a synchronous motor with permanent magnets is a vector control system. The construction of such a system has a number of difficulties, one of them is the need to have information about the current position of the rotor. Data on the position of the rotor can be obtained using sensors, or include a supervisor in the control system. The article describes an adaptive observer of the position and speed of the rotor of a synchronous motor with permanent magnets. This observer is used in the system of sensorless vector control of the electric drive. The presented version of the observer of the engine state is realized by creating a model in the Matlab Simulink software package. The results of experimental verification of the presented observer at the stand with the use of an engine with a power of $200 \mathrm{~W}$ are shown. The aim of the work is to develop an observer that is stable to changing drive parameters. This is achieved by using a relay unit in the view of the observer, which implements the slip mode.
\end{abstract}

\section{Introduction}

At present, non-sensor systems of the electric drive are widespread, in which the measurement of the position of the rotor is performed using special analytical algorithms [15]. Without-sensor control systems of the electric drive can increase the reliability of the drives due to the failure of the signal lines. Determination of the position of the rotor is based on data from sensors that measure currents and voltages in the lines supplying the motor. The observer is a mathematical model of the engine, the input data of which are stator motor currents. Observers are required to be resistant to noise in the measuring channels, to provide a wide range of speed control and a low dependence of the calculation results of the position angle and the rotor speed on the drift of the engine parameters [6-12].

The observer in question has a motor model, as well as a relay controller, which adapts the model to the real processes occurring in the engine. The observer's task is to calculate the position of the back-EMF vector.

\section{Mathematical model}

The model of a synchronous motor with permanent magnets (PMSM) is described in a fixed coordinate system $(\alpha, \beta)$, by the matrix equation: 


$$
\frac{d}{d t} i_{s}=A i_{s}+B\left(v_{s}-e_{S}\right)
$$

The matrices A and B are defined by the expressions: $A=-\frac{R}{L} I, B=\frac{1}{L} I, L=\frac{3}{2} L_{m}$,

where $R$ and $L_{m}$ are active resistance and inductance of the phase winding of the stator, $I$-single matrix with a size $2 \times 2$

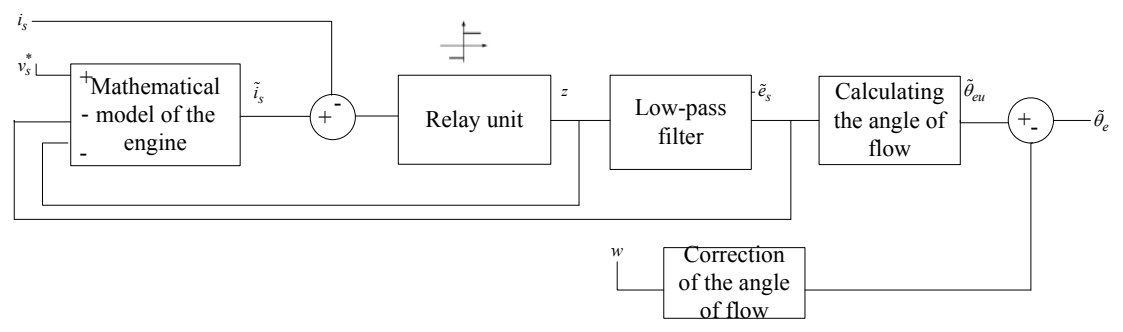

Fig. 1. Block diagram of the algorithm for determining the angle of the rotor flow

The general view of the structure of the adaptive regulator is shown in Fig. 1. The structure includes the mathematical model of the motor, the relay controller, the filter, the rotor flux angle calculator, the rotor flux angle corrector. Taking into account the introduction of the relay unit into the structure of the observer, the expressions on which the calculations occur will have the following form:

$$
\begin{aligned}
\frac{d}{d t} \tilde{i}_{S} & =A \tilde{i}_{S}+B\left(v_{S}^{*}-\tilde{e}_{S}+z\right) \\
z & =k \operatorname{sign}\left(\tilde{i}_{S}-i_{S}\right)
\end{aligned}
$$

where $\tilde{i}_{S}$ is calculated current, $i_{S}$ - measured current, $v_{S}^{*}$-specified voltage on the stator

The goal of the relay controller is to reduce the error between the measured and calculated currents to zero [13-15]. In order to realize the observer in the digital control system, expressions (2) - (3) should be written in a discrete form:

$$
\begin{gathered}
\tilde{i}_{S}(n+1)=F \times \tilde{i}_{S}(n)+G\left(v_{S}^{*}(n)-\tilde{e}_{S}(n)+z(n)\right) \\
z(n)=\operatorname{ksign}\left(\tilde{i}_{S}(n)-i_{S}(n)\right)
\end{gathered}
$$

where $F=I \cdot \exp \left[-\frac{R}{L} T\right], G=\frac{1}{R}\left(1-\exp \left[-\frac{R}{L} T_{S}\right]\right) I, T_{S}$ - carrier period

At the output of the relay controller, the signal contains noises, the most simple means to eliminate them is a low-pass filter [16-20].

Filtering of the feedback EMF signal is performed according to the expression:

$$
\frac{d}{d t} \tilde{e}_{S}=-\omega_{0} \tilde{e}_{S}+\omega_{0} z
$$

where $\omega_{0}=2 \pi f_{0}, f_{0}$ - cutoff frequency

We write expression (6) in a discrete form:

$$
\tilde{e}_{S}(n+1)=\tilde{e}_{S}(n)+2 \pi f_{0}\left(z(n)-\tilde{e}_{S}(n)\right)
$$


the value of the rotor angle is determined from the relation:

$$
e_{S}=\frac{3}{2} k_{e} \omega\left(\begin{array}{c}
-\sin \theta \\
\cos \theta
\end{array}\right)
$$

Thus, the angle of the rotor flow is determined from the magnitude of the projections of the back-EMF on the axis $\alpha$ and $\beta$ according to the expression:

$$
\tilde{\theta}_{e u}=\arctan \left(-\tilde{e}_{s \alpha}, \tilde{e}_{s \beta}\right)
$$

When changing the direction of rotation of the motor, the angle of the rotor flux is corrected by changing the signs in expression (9).

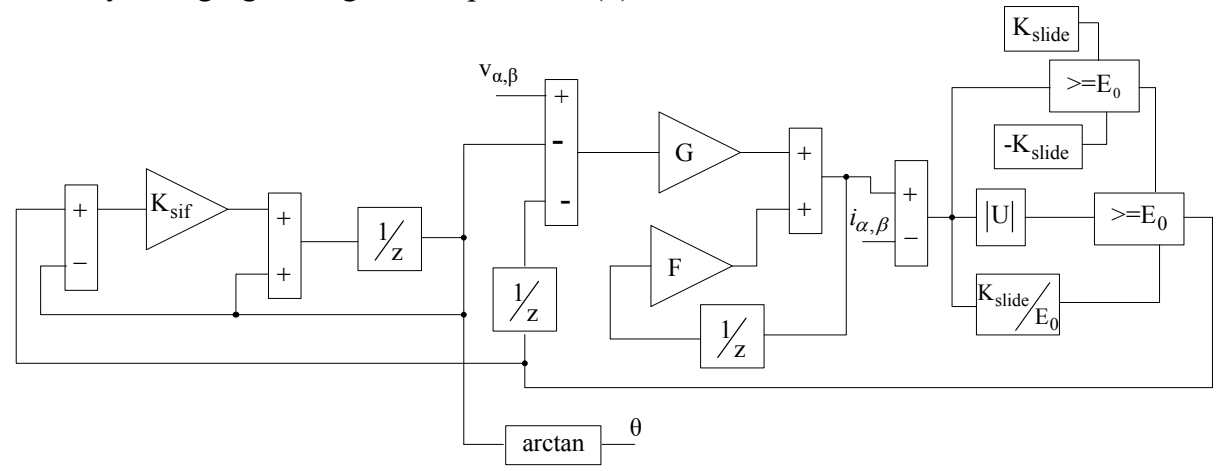

Fig. 2. The scheme of the observer of a state operating on sliding modes

Thus, the structure of the observer using expressions (4) - (9) is shown in Fig. 2. The system of the sliding observer of the state of the synchronous motor with permanent magnets presented in Fig. 2 was implemented in the package of applied programs Matlab Simulink.

Adjustment of the observer occurs by entering the motor's passport parameters: stator resistance, stator inductance, rated voltage, rated current, number of pole pairs, the stator current frequency corresponding to the nominal rotor speed is additionally calculated. The adjustment of the relay unit, by changing the sliding surface, occurs by changing the variables $K_{\text {slide }}$ and $E_{0}$, The cutoff frequency of the low-pass filter is corrected by changing the variable $K_{\text {sif }}$.

The most rapid way to set up an observer is to change the above parameters when simulating a mode in which the motor is forced to rotate at a predetermined frequency and a known position angle, while observing the measured and calculated angle of the rotor position and the shape of the calculated and measured back-EMF [21-25]. In Fig. 3a one can observe oscillograms of the rotor position angle during the observer adjustment, the actual angle by the blue solid line calculated by the red dashed observer, Fig. $3 \mathrm{~b}$ shows oscillograms of the back -EMF calculated along the axes $(\alpha, \beta)$. The criterion of successful adjustment can be considered as the coincidence of the curves calculated by the observer angle with the actual angle of the rotor position, the curves of the back -EMF in this case have a smooth sinusoidal shape [26-28]. 

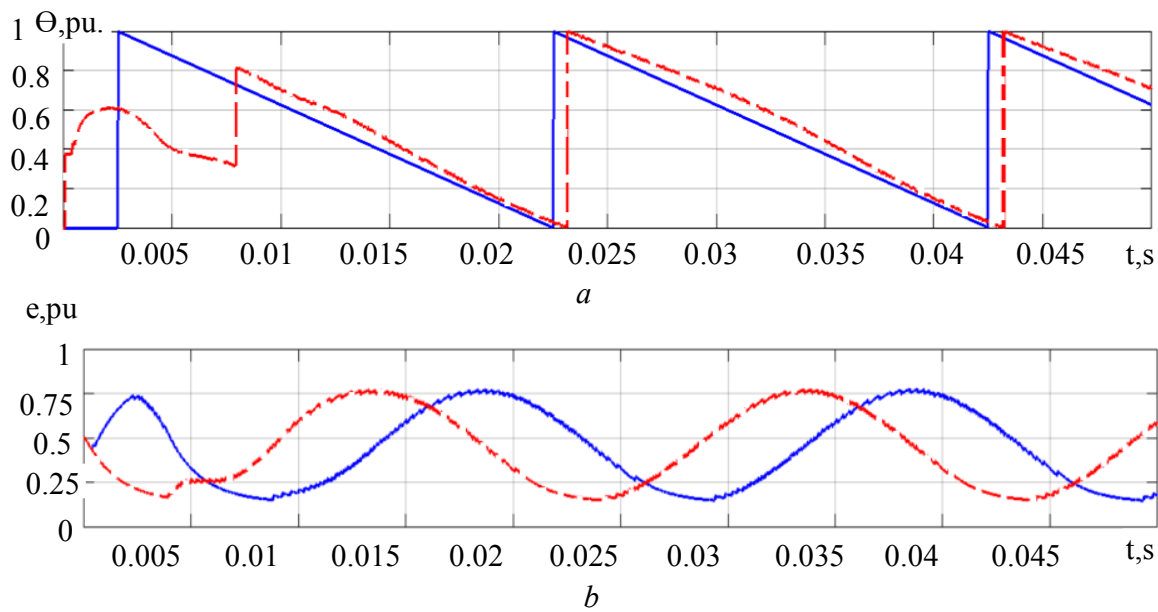

Fig. 3. Diagrams of the angle of the rotor position and the back-EMF during the adjustment of the rotor position observer

\section{Experimental and theoretical investigations}

To assess the effect of engine parameters on the error in calculating the angle of the rotor position, a model was created in the Matlab Simulink software using the Permanent Magnet Synchronous Machine, configured by the engine's passport parameters. A comparison is made of the actual angle of the rotor position and calculated by the observer at a given engine speed. In Fig. 4 shows the oscillogram of the error calculating the angle at the engine's passport parameters.

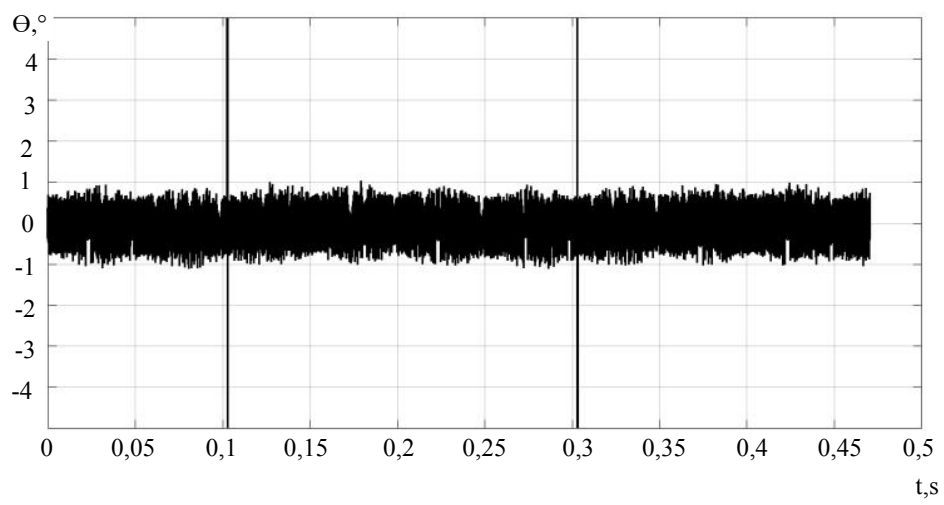

Fig. 4. Oscillogram of the error calculating the angle at the engine's passport parameters

The resistance of the phase winding of the motor in this example is 0.4 ohms at a temperature of $+25^{\circ} \mathrm{C}$, for machines with insulation class $\mathrm{F}$, the temperature of the stator windings can be $140^{\circ} \mathrm{C}$. At a temperature coefficient of copper resistance of 0.004 , the resistance of the stator winding will be $0.58 \mathrm{Ohm}$. Figure 5 shows the dependence of the error in calculating the angle of the rotor position by the observer from the value of the active resistance of the rotor. 


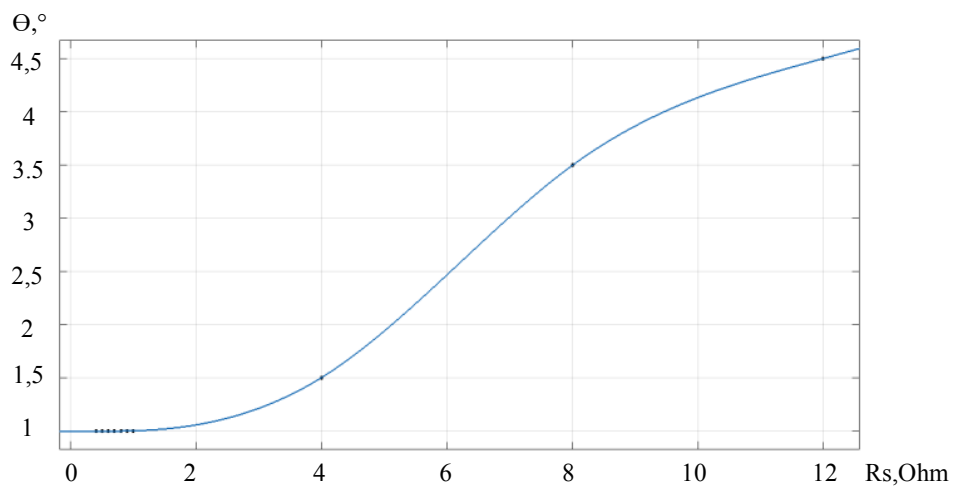

Fig. 5. Dependence of the error in calculating the angle of the rotor position by the observer from the value of the active resistance of the rotor.

When the value of the active resistance of the stator of a certain critical value is reached, the error in calculating the angle increases, and the error in calculating the angle for setting the value of the stator resistance 4 Ohm is shown in Fig. 6.

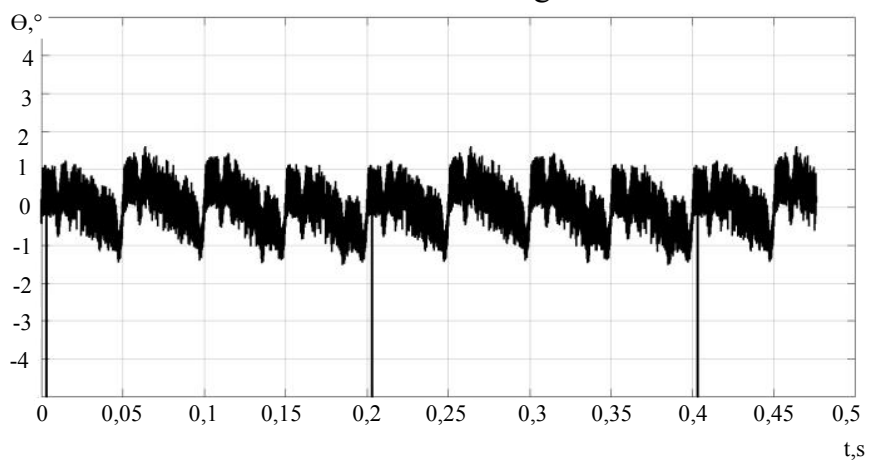

Fig. 6. Error in calculating the angle for setting the value of the stator resistance $4 \mathrm{Ohm}$

The dependence of the error in calculating the angle on the stator inductance is shown in Fig. 7, the oscillogram of the angle calculation error when specifying the inductance value of the stator winding $0.004 \mathrm{H}$ is shown in Fig. 8.

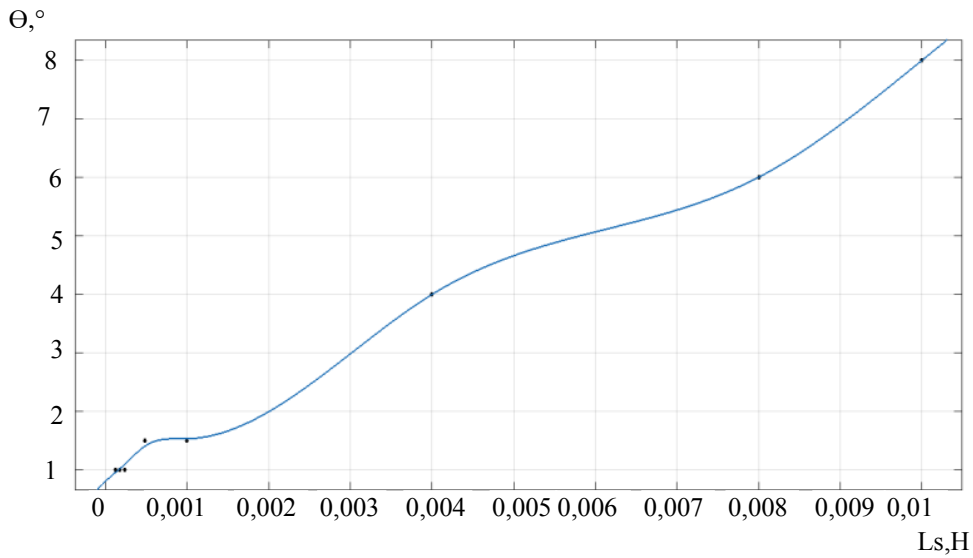

Fig. 7. Dependence of the error in calculating the angle on the stator inductance 
The nominal inductance of the stator phase is $0.0012 \mathrm{H}$

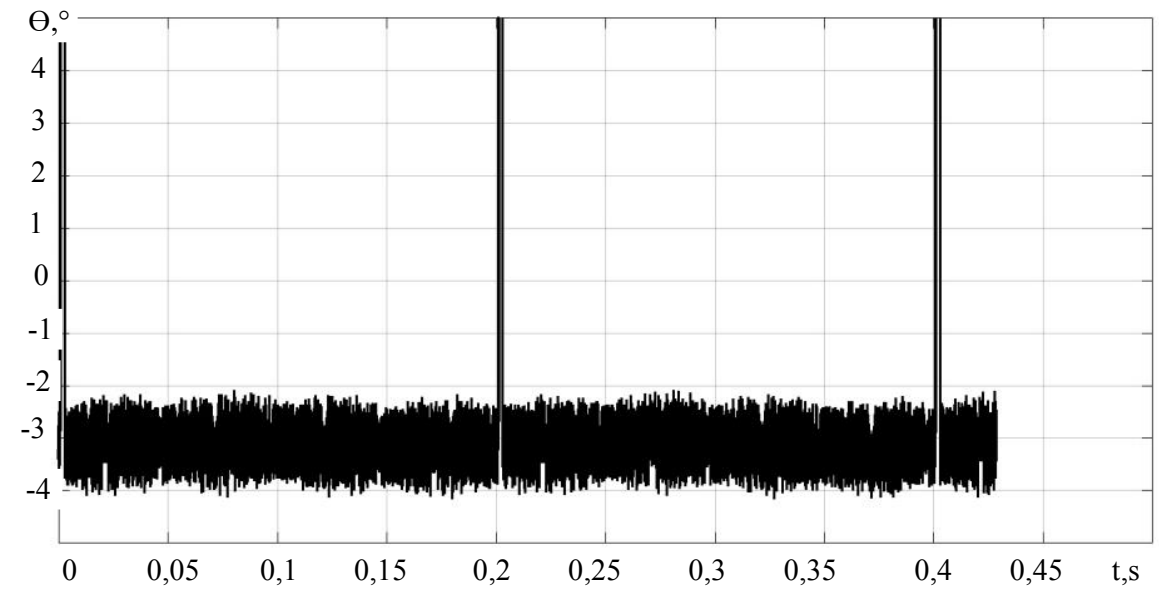

Fig. 8. Error when specifying the inductance value of the stator winding $0.004 \mathrm{H}$

\section{Conclusions}

The article presents the implementation of sensorless control of a synchronous motor with permanent magnets with the use of an adaptive observer working in a sliding mode. To use the observer, two current sensors installed on the lines supplying the motor, knowledge of the reference voltage, as well as the stator parameters of the motor-inductance and capacitance, were required. Figure 5 shows the results of estimating the stability of the observer to the change in the active resistance of the stator winding; from this graph it can be seen that the observer has a stable work zone in which the change in resistance does not affect the magnitude of the error in calculating the angle, a further increase in resistance leads to an increase in the error, In this case, its oscillogram has an oscillatory character, so, with a further increase in the resistance, the trajectory of changing the angle of the rotor position remains. Fig. 7 shows the results of the evaluation of the dependence of the error in calculating the angle of the rotor position on the inductance of the stator winding; in this parameter, the observer also has a margin of stability, a large deviation in the stator inductance leads to a delay in the calculated angle of the rotor position. The presented observer shows good results when calculating the flow angle and rotor speed when the engine parameters deviate from the passport values.

\section{References}

1. R.I. Zhiligotov, V. Ya. Frolov, in Week of Science SPbPU: Materials of the scientific conference with the international. Institute of Energy and Transport Systems. Part 2, 160-162 (2016).

2. Z. Chen, M. Tomita, S. Doki, and S. Okuma, IEEE Trans. Industrial Electronics 50, 288295 (2003).

3. S.V. Drakunov, in Proceedings of the 31st Conference on Decision and Control, Tucson, Arizona, 2368-2369 (2010)

4. R. Ortega, L. Praly, A. Astolfi, .T. Lee, and K. Nam, Control Systems Technology, IEEE Transactionson 99, 1-13 (2010).

5. C. Edwards and S.K. Spurgeon, International Journal of Control 59,1211-1229 (1994). 
6. C. Edwards and S.K. Spurgeon, International Journal of Control 64, 967-983 (1996).

7. C. Edwards and S.K. Spurgeon, International Journal of Robust and Nonlinear Control 7, 337-351 (1997).

8. C. Edwards and S.K. Spurgeon, Sliding Mode Control: Theory and Applications, Taylor\& Francis, 237 (1998).

9. C. Edwards and S.K. Spurgeon, European Journal of Control 6, 341-356 (2000).

10. C. Edwards, S.K. Spurgeon, and R.J. Patton, Automatica 36, 541-553 (2000).

11. D. Janiszewski, Studies in Automation and Information Technology 28/29, 79-90 (2004).

12. S. Morimoto, K. Kawamoto, M. Sanada, and Y. Takeda, Proc. 2001 IEEE IAS Annual Meeting 4, 2637-2644 (2001).

13. M. Pacas, IEEE Industrial Electronics Magazine 5, 16-23 (2011)

14. P. Pillay, R. Krishnan, IEEE Transactions on Industrial Electronics 35, 537-541 (1988).

15. A.M. Trzynadlowski, R.L. Kirlin, S.F. Legowski, IEEE Transactions on Industrioal Electronics 44, 173-181 (1997).

16. V. I. Utkin, IEEE Transactions on Industry Electron 40, 23-36 (1993).

17. V. I. Utkin, J. Guldner, and J. Shi, Sliding Mode Control in Electromechanical Systems, Taylor \& Francis, 325 (1997).

18. V.I. Utkin, IEEE Transactions on Automatic Control 2, 212-222 (1977).

19. V.I. Utkin, Sliding Modes in Control Optimization, Springer-Verlag, Berlin, 286 (1992)

20. Z. Yan and V. Utkin, In: Conf. Rec. IEEE-IES 28th Annu. Meeting IECON 2002 3, 1842-1847 (2004)

21. Y. Alexandrova, K. Kamiev, V. Zaboin, J. Pyrhönen, International Review of Electrical Engineering 10, 678-686 (2015), doi:10.15866/iree.v10i5.7257

22. A.I. Korshunov, Russian Electrical Engineering 85, 150-155 (2014), doi:10.3103/S1068371214030080

23. A.E. Bolotin, D.B. Selyukin, Teoriya i Praktika Fizicheskoy Kultury 32-34 (2015)

24. V.M. Borovkov, L.V. Zysin, V.V. Sergeev, Izvestiya Akademii Nauk. Energetika (6) (2002)

25. A. Kalimov, S. Shimansky, IEEE Transactions on Magnetics 51, (2015), doi:10.1109/TMAG.2014.2362961

26. M.R. Petritchenko, E.V. Kotov, D.V. Nemova, D.S. Tarasova, V.V. Sergeev, Magazine of Civil Engineering 77 (1) (2018)

27. I.Z. Boguslavskii, I.Y. Kruchinina, A.S. Lyubimtsev, Y.F. Khozikov, V.V. Pal'tseva, Russian Electrical Engineering 87, 206-210 (2016), doi:10.3103/S1068371216040039

28. K. Kamiev, J. Nerg, J. Pyrhönen, V. Zaboin, J. Tapia, IEEE Transactions on Industrial Electronics 61, 5075-5085 (2014), doi:10.1109/TIE.2013.2289871 